\title{
Oral Lichen Planus : A Review
}

\author{
Rohini Salvi ${ }^{1}$, Rohit Bhailal Gadda ${ }^{2}$,Varun Gul Bhatia ${ }^{3}$
}

\begin{abstract}
Oral lichen planus (OLP) is a chronic mucosal condition commonly encountered in clinical dental practice. Lichen planus is believed to represent an abnormal immune response in which epithelial cells are recognized as foreign, secondary to changes in the antigenicity of the cell surface. It has various oral manifestations, the reticular form being the most common. The erosive and atrophic forms of OLP are less common, yet are most likely to cause symptoms. Topical corticosteroids constitute the mainstay of treatment for symptomatic lesions of OLP. Recalcitrant lesions can be treated with systemic steroids or other systemic medications. However, there is only weak evidence that these treatments are superior to placebo. Given reports of a slightly greater risk of squamous cell carcinoma developing in areas of erosive OLP, it is important for clinicians to maintain a high index of suspicion for all intraoral lichenoid lesions. Periodic follow-up of all patients with OLP is recommended.
\end{abstract}

Key words: Diagnosis of OLP, Review

\section{Introduction}

Lichen planus is a relatively common disorder, estimated to affect $0.5 \%$ to $2.0 \%$ of the general population. ${ }^{1}$ It is a chronic, inflammatory disease that affects mucosal and cutaneous tissues. Approximately half of the patients with cutaneous lichen planus have oral involvement. ${ }^{2}$ However, mucosal involvement can be the sole manifestation in up to $25 \%$ of affected population. ${ }^{2}$ Oral lichen planus has a peak incidence in middle age patients and has female predominance of $2: 1 .^{3}$ It is characteristically associated with persistent clinical course and resistance to most conventional treatments.

\section{Clinical Features}

There are various clinical morphological manifestations of the disease (Table 1). More than one clinical subtype can co-exist in the same patient. The reticular $(92 \%)$, plaque $(36 \%)$ and papule (11\%) types are usually asymptomatic and require no specific

Professor and Head ${ }^{1}$

Senior Lecturer ${ }^{2}$

Senior Lecturer ${ }^{3}$

Department of Oral Medicine \& Radiology,

M.G.M. Dental College and Hospital, Navi Mumbai

Address for Correspondence:

Dr. Rohit Bhailal Gadda

Senior Lecturer

Department of Oral Medicine \& Radiology,

M.G.M. Dental College and Hospital, Navi Mumbai

E-mail: rohitgadda@gmail.com
Table 1: Clinical Presentation of Oral Lichen Planus

\begin{tabular}{|l|l|l|}
\hline Symptom & $\begin{array}{l}\text { Clinical } \\
\text { types }\end{array}$ & Description \\
\hline Asymptomatic & Reticular & $\begin{array}{l}\text { Wickham's striae } \pm \text { discrete } \\
\text { erythematous border }\end{array}$ \\
\hline Plaque-like & $\begin{array}{l}\text { Resemble leukoplakia, } \\
\text { common in smokers }\end{array}$ \\
\hline Symptomatic & Atrophic & $\begin{array}{l}\text { Diffuse red patch, peripheral } \\
\text { radiating white striae, chronic } \\
\text { desquamative gingivitis }\end{array}$ \\
\hline & Erosive & $\begin{array}{l}\text { Irregular erosion covered } \\
\text { with a pseudomembrane }\end{array}$ \\
\hline & Bullous & $\begin{array}{l}\text { Small bullae or vesicles that } \\
\text { may rupture easily }\end{array}$ \\
\hline
\end{tabular}

treatment. ${ }^{4}$ On the other hand, the atrophic (44\%), erosive (9\%) and bullous (1\%) types usually cause severe burning pain and are refractory to conventional treatments. ${ }^{4}$

The lesions are usually symmetrical. It frequently affects buccal mucosa, tongue, gingiva, lip and palate. Extra-oral mucosal involvements include the anogenital area (vulvovaginal-gingival syndrome), conjunctivae, oesophagus or larynx.

\section{Differential Diagnosis}

The diagnosis of OLP can be rendered more confidently when characteristic cutaneous lesions are present. Except for the pathognomonic appearance of reticular 
OLP (white striae occurring bilaterally on the buccal mucosa), in most cases histopathologic evaluation of lesional tissue is required to obtain a definitive diagnosis.

The differential diagnosis of erosive OLP includes squamous cell carcinoma, discoid lupus erythematosus, chronic candidiasis, benign mucous membrane pemphigoid, pemphigus vulgaris, chronic cheek chewing, lichenoid reaction to dental amalgam or drugs, graft-versus-host disease (GVHD), hypersensitivity mucositis and erythema multiforme. ${ }^{5}$ The plaque form of reticular OLP can resemble oral leukoplakia.

The classic histopathologic features of OLP include liquefaction of the basal cell layer accompanied by apoptosis of the keratinocytes, a dense band-like lymphocytic infiltrate at the interface between the epithelium and the connective tissue, focal areas of hyperkeratinized epithelium (which give rise to the clinically apparent Wickham's striae) and occasional areas of atrophic epithelium where the rete pegs may be shortened and pointed (a characteristic known as sawtooth rete pegs. ${ }^{5}$ Although the histopathologic features of OLP are characteristic, other conditions, such as lichenoid reaction to dental amalgam and drugs, may exhibit a similar histologic pattern.

The histopathologic diagnosis of OLP can be complicated by the presence of superimposed candidiasis; diagnosis can also be more difficult if the biopsy exhibits an ulcerated surface. In these situations, the biopsy findings are sometimes interpreted as representing a nonspecific chronic inflammatory process. ${ }^{6}$ On occasion, the histo-pathologic features are equivocal, and the oral pathologist examining the submitted tissue may recommend that a second biopsy be performed to obtain fresh tissue for immunofluorescence. ${ }^{7}$ Immunofluorescent examination of OLP lesional tissue usually demonstrates deposition of fibrinogen along the basement membrane zone.

\section{Clinical Significance}

OLP is one of the most common mucosal conditions affecting the oral cavity. ${ }^{8}$ Therefore dentists in clinical practice will regularly encounter patients with this condition. Because patients with the atrophic and erosive forms of OLP typically experience significant discomfort, knowledge of the treatment protocols available is important. The similarity of OLP to several other vesiculoulcerative conditions, some of which can lead to significant morbidity, makes accurate diagnosis essential. For example OLP and GVHD can have similar histologic and clinical presentations. GVHD is a serious condition that occurs in bone marrow transplant patients when transplanted marrow cells react against host tissues. The extent of oral involvement is highly predictive of the severity and prognosis of GVHD. ${ }^{9}$

Erosive OLP and lichenoid drug reactions can be indistinguishable both histologically and clinically. Some of the drugs commonly associated with lichenoid reactions are nonsteroidal anti-inflammatory drugs, diuretics, angiotensin-converting enzyme inhibitors, beta-blockers and antimicrobials. ${ }^{10}$

It is also necessary to distinguish isolated erosive or reticular lesions from lichenoid reactions to dental amalgam. ${ }^{11}$ Lichenoid reactions to amalgam do not migrate, they occur on mucosal tissue in direct contact with the restoration, and they resolve once amalgam restoration is removed. ${ }^{11}$ Some studies indicate an increased risk of squamous cell carcinoma in patients with OLP lesions. ${ }^{12-15}$ This increased risk appears most common with the erosive and atrophic forms and in cases of lesions of the lateral border of the tongue. Other studies suggest that in some cases of purported malignant transformation, the malignancy may not have developed from true lesions of OLP but may instead have arisen from areas of dysplastic leukoplakia with a secondary lichenoid inflammatory infiltrate. ${ }^{16,17}$ A review of previously published studies concluded that the risk of developing squamous cell carcinoma in patients with OLP is approximately 10 times higher than that in the unaffected general population. ${ }^{18}$ Other published reports have noted a possible association between OLP and hepatitis $\mathrm{C},{ }^{19}$ sclerosing cholangitis, and primary biliary cirrhosis. ${ }^{20}$

\section{Treatment}

There is currently no cure for OLP. Excellent oral hygiene is believed to reduce the severity of the symptoms, but it can be difficult for patients to achieve high levels of hygiene during periods of active disease. Treatment is aimed primarily at reducing the length and severity of symptomatic outbreaks. Asymptomatic reticular and plaque forms of OLP do not require pharmacologic intervention. Algorithm for the management of oral lichen planus is shown in Fig. $1 .{ }^{21}$ 
Fig. 1: Algorithm for the management of oral lichen planus

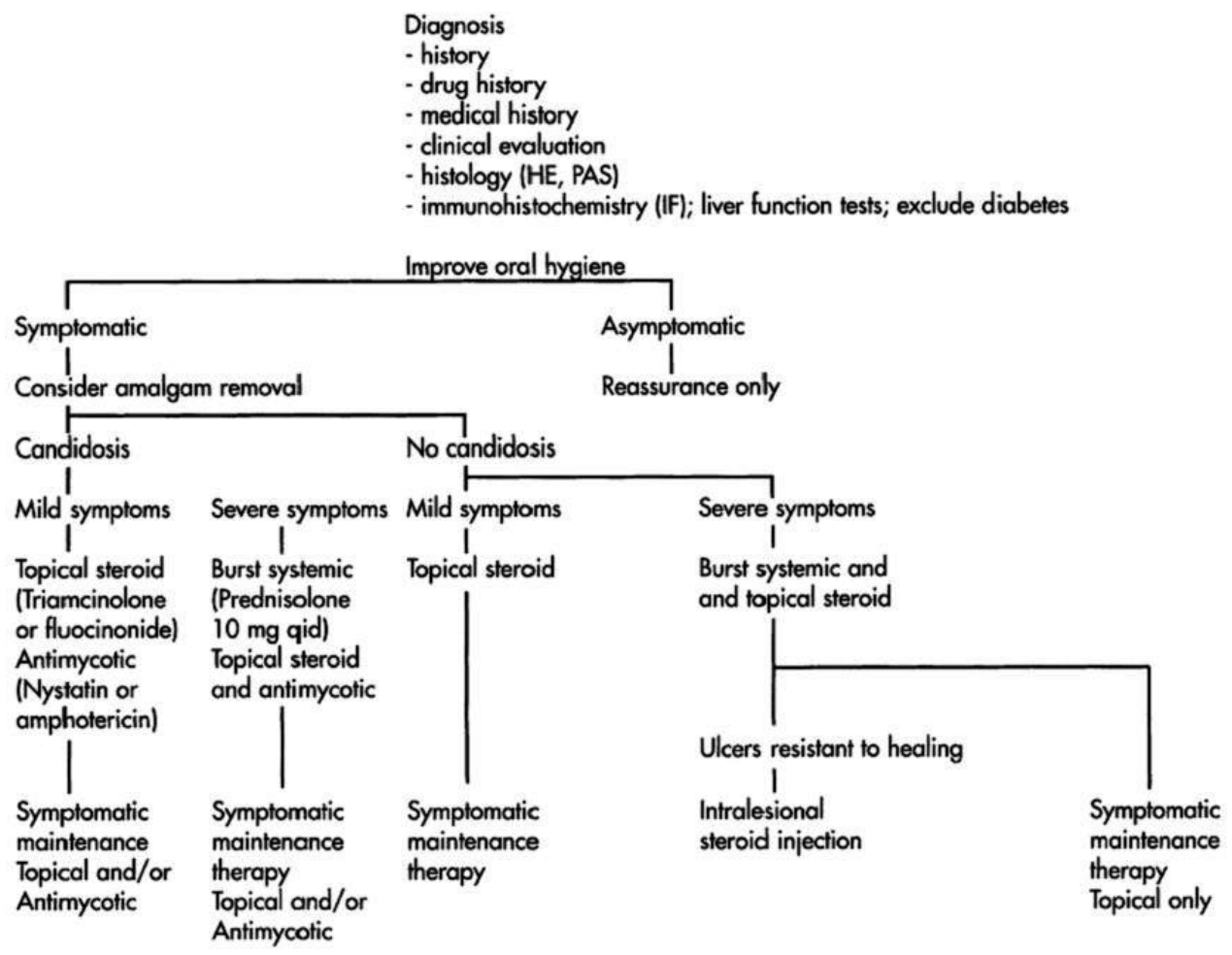

\section{Corticosteroids}

The most widely accepted treatment for lesions of OLP involves topical or systemic corticosteroids to modulate the patient's immune response. Topical corticosteroids are the mainstay in treating mild to moderately symptomatic lesions. Options (presented in terms of decreasing potency) include $0.05 \%$ clobetasol propionate gel, $0.1 \%$ or $0.05 \%$ betamethasone valerate gel, $0.05 \%$ fluocinonide gel, $0.05 \%$ clobetasol butyrate ointment or cream, and $0.1 \%$ triamcinolone acetonide ointment. ${ }^{22}$ Patients are instructed to apply a thin layer of the prescribed topical corticosteroid up to 3 times a day, after meals and at bedtime. The gel or ointment can be applied directly or can be mixed with equal parts Orabase(a gelatin-pectin-sodium carboxymethylcellulose-based oral adhesive paste, ConvaTec, Division of Bristol-Myers Squibb, Montreal, Que.) to facilitate adhesion to the gingival tissues. These solutions can be prepared by a compounding pharmacy. Patients should be instructed to gargle with $5 \mathrm{~mL}$ of the solution for 2 minutes after meals and at night. After rinsing, the solution should be expectorated, and nothing should be taken by mouth for one hour. Alternative delivery methods include the use of custom trays to serve as reservoirs for the corticosteroid. The advantage of topical steroid application is that side effects are fewer than with systemic administration. Adverse effects include candidiasis, thinning of the oral mucosa and discomfort on application. Topical

formulations of the more potent corticosteroids can cause adrenal suppression if used in large amounts for prolonged periods or with occlusive dressings. The lowest-potency steroid that proves effective should be used. Intralesional injection of corticosteroid for recalcitrant or extensive lesions involves the subcutaneous injection of $0.2-0.4 \mathrm{~mL}$ of a $10 \mathrm{mg} / \mathrm{mL}$ solution of triamcinolone acetonide by means of a 1.0$\mathrm{mL} 23^{-}$or 25-gauge tuberculin syringe.

Systemic steroid therapy should be reserved for patients in whom OLP lesions are recalcitrant to topical steroid management. Dosages should be individualized according to the severity of the lesions and the patient's weight and should be modified on the basis of the patient's response to treatment. The oral dose of prednisone for a $70-\mathrm{kg}$ adult ranges from $10-20 \mathrm{mg} /$ day for moderately severe cases to as high as $35 \mathrm{mg} /$ day $\left(0.5 \mathrm{mg} / \mathrm{kg}\right.$ daily) for severe cases. ${ }^{23}$ Prednisone should be taken as a single morning dose to reduce the potential for insomnia and should be taken with food to avoid nausea and peptic ulceration. Significant response should be observed within one to 2 weeks.

\section{Other Treatment Modalities}

Twice-daily topical application of compounded $0.1 \%$ tacrolimus ointment was recently reported to be effective in controlling symptoms as well as clearing lesions of OLP. ${ }^{24}$ Tacrolimus is a macrolide immunosuppressant with a mechanism of action 
similar to that of cyclosporine, but is 10 to 100 times more potent and is better able to penetrate the mucosal surface. ${ }^{24}$

Other documented treatment modalities include retinoids and vitamin A analogues, cyclosporine rinse, the immunomodulating agent levamisole, PUVA treatment (which consists of administration of 8methoxypsoralen and exposure to long-wave ultraviolet A light), dapsone, griseofulvin, azathioprine and cryotherapy. ${ }^{25}$ Even though evidence of the efficacy of these treatment approaches is not overwhelming, corticosteroid therapy remains the most common approach for managing symptomatic lesions. Because of the possibility of increased risk of malignant transformation, periodic reassessment of all patients with OLP is recommended.

\section{Conclusion}

Patients with OLP should be counselled as to the nature of this chronic condition and the different approaches to treatment. Patients should be informed that they may experience alternating periods of symptomatic remission and exacerbation. Clinicians should maintain a high index of suspicion for all intraoral areas that appear unusual, even in patients with a histologically confirmed diagnosis of OLP. This vigilance is especially important for isolated lesions occurring in locations at higher risk for the development of squamous cell carcinoma, such as the lateral and ventral surfaces of the tongue and the floor of the mouth.

\section{References}

1. McCreary CE, McCartan BE. Clinical management of lichen planus. Brit J Oral Maxillofacial Surg 1999; 37(5):338-43.

2. Mollaoglu N. Oral lichen planus: a review. Br J Oral Maxillofac Surg 2000;38:370-7.

3. Setterfield JF, Black MM, Challacombe SJ. The management of oral lichen planus. Clin Exp Dermatol 2000;25:176-82.

4. Thorn JJ, Holmstrup P, Rindum J, et al. Course of various clinical forms of oral lichen planus. A prospective followup study of 611 patients. J Oral Pathol 1988;17:213-8.

5. Regezzi JA, Sciubba JJ. Oral pathology: clinical pathologic correlations. 3rd ed. Philadelphia: WB Saunders; 1999.

6. Burgess KL, McComb RJ. The gingivae in dermatoses. Ont Dent 1997; 74(5):25-9.
7. Murrah VA, Perez LM. Oral lichen planus: parameters affecting accurate diagnosis and effective management. Pract Periodontics Aesthet Dent 1997; 9(6):613-20.

8. Pynn BR, Burgess KL, Wade PS, McComb RJ. A retrospective survey of 2021 patients referred to the Toronto Hospital Mouth Clinic. Ont Dent 1995; 72(1):21-4.

9. Neville BW, Damm DD, Allen CM, Bouquot JE. Oral and maxillofacial pathology. 2nd ed. Philadelphia: WB Saunders; 2002.

10. Bernstein ML. The diagnosis and management of chronic nonspecific mucosal lesions. J Calif Dent Assoc 1999; 27(4):290-9.

11. Ostman PO, Anneroth G, Skoglund A. Oral lichen planus lesions in contact with amalgam fillings: a clinical, histologic, and immunohistochemical study. Scand J Dent Res 1994; 102(3):172-9.

12. 17. Silverman S Jr, Bahl S. Oral lichen planus update: clinical characteristics, treatment responses, and malignant transformation. Am J Dent 1997; 10(6):259-63.

13. Barnard NA, Scully C, Eveson JW, Cunningham S, Porter SR. Oral cancer development in patients with oral lichen planus. J Oral Pathol Med 1993; 22 (9):421-4.

14. Holmstrup P. The controversy of a premalignant potential of oral lichen planus is over. Oral Surg Oral Med Oral Pathol 1992; 73(6):704-6.

15. Silverman S. Oral lichen planus: a potentially premalignant lesion. J Oral Maxillofacial Surg 2000; 58(11):1286-8.

16. Eisenberg E, Krutchkoff DJ. Lichenoid lesions of oral mucosa. Diagnostic criteria and their importance in the alleged relationship to oral cancer. Oral Surg Oral Med Oral Pathol 1992; 73(6):699-703.

17. Eisenberg E. Oral lichen planus: a benign lesion. J Oral Maxillofacial Surg 2000; 58(11):1278-85.

18. Drangsholt M, Truelove EL, Morton TH Jr, Epstein JB. A man with a thirty-year history of oral lesions. J Evid Base Dent Pract 2001; 1(2):123-35.

19. Bellman B, Reddy RK, Falanga V. Lichen planus associated with hepatitis C. Lancet 1995; 346(8984):1234.

20. Fantasia JE. Diagnosis and treatment of common oral lesions found in the elderly. Dent Clin North Am 1997; 41(4):877-90.

21. Oliver GF, Winkelman RK. Treatment of lichen planus. Drugs 1993; 45;56-6

22. Vincent SD. Diagnosing and managing oral lichen planus. JADA 1991; 122(6):93-6.

23. Carrozzo M, Gandolfo S. The management of oral lichen planus. Oral Dis 1999; 5(3):196-205.

24. Kaliakatsou F, Hodgson TA, Lewsey JD, Hegarty AM, Murphy AG, Porter SR. Management of recalcitrant ulcerative oral lichen planus with topical tacrolimus. J Am Acad Dermatol 2002; 46(1):35-41.

25. Carrozzo M, Gandolfo S. The management of oral lichen planus. Oral Dis 1999; 5(3):196-205. 